\title{
Epidemiology, management, and prognosis of malignant large bowel polyps within a defined population
}

Registre des Tumeurs Digestives (Equipe associée INSERM-DGS)

Faculté de Médecine, 21033 Dijon Cédex, France

$M$ J Chantereau

$\mathrm{J}$ Faivre

M C Boutron

F Piard

P Arveux

L Bedenne

$P$ Hillon

Correspondence to:

Professor J Faivre, Faculté de Médecine, 7 Boulevard Jeanne d'Arc 21033 DIJON, France.

Accepted for publication 13 May 1991

\author{
M J Chantereau, J Faivre, M C Boutron, F Piard, P Arveux, L Bedenne, P Hillon
}

\begin{abstract}
The population based registry of digestive tract tumours established for the department of Côte d'Or, France (population 480 000) was used to study the epidemiology and management of malignant large bowel polyps. In a 10 year period (1976-85), 146 cases were recorded in the area. Age standardised incidence rates were 2.7 per 100000 for men and 1.4 per 100000 for women. Although incidence rates increased significantly during the study period, large bowel cancer diagnosed as a malignant polyp remained relatively rare $(6 \cdot 2 \%$ of all registered large bowel cancers). Two malignant polyps $(1.4 \%)$ were less than $1 \mathrm{~cm}$ in diameter, $34(23.3 \%)$ were more than $30 \mathrm{~mm}$. Sixty patients were treated by endoscopic polypectomy, four by contact radiotherapy, 21 by surgical local excision, 58 by colectomy (10 preceded by polypectomy), and three by colotomy. Operative mortality was $8 \cdot 2 \%$ after intra-abdominal surgery, $4.8 \%$ after local surgical excision, and $0 \%$ after polypectomy $(p<0.05)$. All deaths occurred in patients over 65 years. The five year cumulative recurrence rates were $8.9 \%$ after surgical excision and $11 \cdot 3 \%$ after endoscopic polypectomy (NS). The corresponding five year net survival rates were $86 \cdot 1 \%$ and $95.9 \%$. Endoscopic excision alone can be considered a sufficient treatment for adenomas with malignant change unless there is evidence of incomplete resection or a high risk of lymph node metastases.
\end{abstract}

For several years clinicians and epidemiologists have shown particular interest in malignant colorectal polyps. One of the reasons is that these lesions have been more frequently diagnosed in the past decade with the development of colonoscopy and their removal may reduce the severity

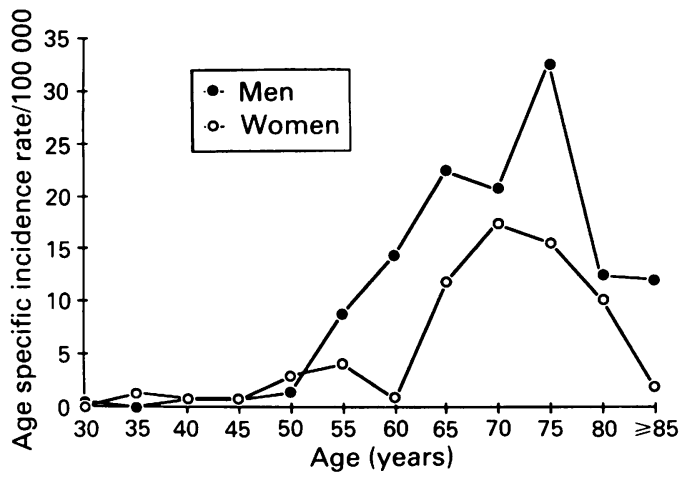

Figure 1: Age specific incidence rates for malignant large bowel polyps by sex in the Côte D'or(1976-85). of colorectal cancers. Unfortunately, data on the epidemiology of malignant colorectal polyps are scarce. Furthermore, what is the best treatment for these patients remains controversial. ${ }^{1+}$ Some authors recommend a secondary segmental resection in an attempt to remove any residual tumour in the bowel wall or in lymph nodes, whereas others believe that polypectomy alone is sufficient. Thus, the aim of this study was to provide data on the incidence and some of the characteristics of malignant colorectal polyps in a well defined French population and to obtain an overview of different treatments and prognostic factors.

\section{Patients and methods}

PATIENTS

A population based registry records all patients with colorectal tumours among the population of the department of Côte d'Or, France (480000 according to the 1982 census). The study included all cases of malignant colorectal polyps diagnosed between 1 January 1976 and 31 December 1985 in the Côte d'Or. They were defined as lesions with the gross appearance of a polyp and histological evidence of carcinoma. Some $46 \%$ of the population live in the town of Dijon, $17 \%$ in smaller towns, and $37 \%$ in rural areas. Medical facilities are abundant. There were 85 hospital beds per 1000 inhabitants, one private general practitioner per 600 inhabitants, and one gastroenterologist practicing colonoscopy per 30000 inhabitants.

\section{STUDY PROTOCOL}

Information was collected from pathology laboratories, university hospitals, local hospitals, surgeons, gastroenterologists, and general practitioners. Because of the keen particpation of the whole medical profession in the Department, we assume that all newly diagnosed polyps and carcinomas were registered. Patients with an invasive large bowel carcinoma associated with a malignant polyp and those with familial polyposis syndrome were excluded.

Details of the patient's age, sex, place of residence, and date of diagnosis, histopathology of polyps (localisation, size, gross morphological appearance, histological type), and type of treatment were obtained from clinicians and pathologists. Original histological slides were collected and reviewed by one pathologist. Histological typing was done according to the World Health Organisation classification. ${ }^{5}$ The degree of invasion was classified as follows: grade 
0 , intramucosal carcinoma, that is malignant cells extending beyond the limits of the glands into the lamina propria but not extending through the muscularis mucosae (polyps with only severe dysplasia were not included); grade 1 , carcinoma invading the muscularis mucosae into the submucosa but above the muscularis propria; grade 2, carcinoma invading the muscularis propria. Other recorded histological features included the histological grade of the carcinoma (well, moderately, or poorly differentiated) and the presence of mucinous component. For resected specimens, the total number of lymph nodes which were positive or negative for carcinoma was recorded, as well as the status of the surgical resection margin. In case of surgery after a previous polypectomy, the presence of residual adenoma or carcinoma was assessed. Operative mortality was defined as death within 30 days of treatment.

Follow up was carried out in November $1989-$ that is up to a minimum of four years for each patient. The follow up data included the patient's status (dead or alive), the cause of death, and the disease status (local recurrence or distant metastasis, or both, or disease free). The development of metachronous colorectal cancer was also investigated. Only in two patients $(1 \cdot 4 \%)$ was the follow up incomplete.

\section{STATISTICAL ANALYSIS}

Population data used in calculating incidence rates were based on estimates of the Côte d'Or population by age and sex calculated annually by the Institut National de la Statistique et des Études Économiques (INSEE) by extrapolation from the 1975 and 1982 censuses. Incidence rates have been standardised by the direct method using the world standard population. To describe the time trend in cancer incidence, an exponential curve of the form $y=a e^{b t}$ was fitted to the annual age standardised incidence rates by means of a regression technique which enables a direct interpretation of the mean annual proportional percentage change.

The crude survival rates were calculated using the life table method. Recurrence rates were analysed in the same way. Net survival rates were calculated by considering only mortality due to large bowel cancer and thus treating deaths from other causes as censored observations. Survival curves and recurrence curves were compared with the log rank test.

\section{Results}

\section{INCIDENCE}

A total of 146 malignant colorectal polyps, 85 in men and 61 in women, were diagnosed in Côte d'Or residents between 1976 and 1985. The crude annual incidence rates were 3.7 per 100000 for men and 2.5 per 100000 for women. The corresponding age standardised rates were 2.7 and 1.4 . The sex ratio was 1.9 . Malignant polyps represented $6.2 \%$ of the 2357 registered cases of large bowel cancers and 3.9\% of the 3704 registered cases with large bowel polyps.

Age specific incidence rates are given in
Figure 1. The incidence rose rapidly with age, but more steeply in men than in women until age 79 years. After this age, the incidence decreased in both sexes. Malignant polyps were rare before age 55 (5.8\% of the cases). The mean (SD) age of the patients at the time of diagnosis was $67 \cdot 7$ $(9 \cdot 7)$ for men and $68 \cdot 6(11 \cdot 3)$ for women (NS).

Incidence rates rose progressively between 1976 and 1985 for both colonic and rectal malignant polyps. The annual increases were $15 \cdot 0(7 \cdot 4) \%$ for colonic malignant polyps $(\mathrm{p}<0.001)$ and $8.3(8.2) \%$ for rectal malignant polyps $(\mathrm{p}<0.05)$.

\section{MORPHOLOGICAL CHARACTERISTICS}

The location of malignant polyps in the large bowel was as follows: rectum ampulla, 36 cases $(24 \cdot 7 \%)$; rectosigmoid junction, 28 cases (19.2\%); sigmoid, 71 cases $(48.6 \%)$; the descending colon: 4 cases $(2 \cdot 7 \%)$; the transverse colon (including flexures), five cases ( $3 \cdot 4 \%)$; and caecoascending colon, two cases $(1 \cdot 4 \%)$. This distribution was not influenced by sex.

The mean (SD) size of malignant polyps was $24 \cdot 2(13 \cdot 2) \mathrm{mm}$. Two polyps were between 5 and $9 \mathrm{~mm}$ in diameter $(1.4 \%)$, eight between 10 and $14 \mathrm{~mm}(5 \cdot 6 \%), 45$ between 15 and $19 \mathrm{~mm}$ $(30 \cdot 8 \%), 56$ between 20 and $29 \mathrm{~mm}(38 \cdot 4 \%), 34$ were more than $30 \mathrm{~mm}(23.3 \%)$, and size was not available in one case. The proportion of large adenomas, (more than $30 \mathrm{~mm}$ in diameter) was higher in the rectum $(30.2 \%)$ and the right colon $(30.0 \%)$ than in the left colon $(14.7 \% ; \mathrm{p}<0.01)$. Among the malignant polyps, $64(43.8 \%)$ were pedunculated, $74(50 \cdot 7 \%)$ were sessile, and in 8 $(5 \cdot 5 \%)$ no description of the gross morphological appearance was available. Malignant polyps under $2 \mathrm{~cm}$ in diameter were more often pedunculated $(54 \cdot 1 \%)$ than the larger ones $(45 \cdot 9 \%$; NS).

\section{HISTOLOGICAL DATA}

Of 146 malignant polyps, $34(23 \cdot 2 \%)$ were limited to the mucosa, $95(65 \cdot 1 \%)$ had extended into the submucosa, and $17(11.6 \%)$ into the muscularis propria. The carcinoma was more frequently invasive in sessile polyps $(89 \cdot 2 \%)$ than in pedunculated polyps $(65.6 \% ; \mathrm{p}<0.001)$. Of the 146 adenocarcinomas, 64 were well differentiated, 75 were moderately differentiated, one was poorly differentiated, one was mucinous, and five could not be classified.

The adenoma remnants were classified as tubular in 62 cases, tubulovillous in 60 , and villous in 18. In six cases no associated adenomatous tissue could be identified histologically within sessile polyps: they were classified as polypoid carcinoma.

\section{TREATMENT}

Of the 146 malignant polyps, 60 were removed by colonoscopic polypectomy $(41 \cdot 1 \%)$, completed in one case by contact radiotherapy. Between 1976 and 1980 endoscopic polypectomy was performed in 16 of 51 cases $(31.4 \%)$, but this rose to 44 of 95 patients between 1981 and 1985 $(43 \cdot 3 \%)$ (NS). Twenty one patients with malig- 
TABLE I Treatment of malignant polyps in the Côte D'or according to site, stage of diagnosis, size, and gross morphological appearance

\begin{tabular}{|c|c|c|c|c|c|c|c|c|c|c|c|c|c|c|c|c|c|c|}
\hline & \multicolumn{4}{|l|}{ Site } & \multicolumn{6}{|c|}{ Grade of invastion } & \multicolumn{4}{|c|}{ Sizet } & \multicolumn{4}{|c|}{ Gross morphology $\neq$} \\
\hline & $\begin{array}{l}\text { Color } \\
\text { No }\end{array}$ & ${ }^{n}(\%)$ & $\begin{array}{l}\text { Rec } \\
\text { No }\end{array}$ & $u_{(\%)}$ & $\stackrel{0}{\text { No }}$ & $(\%)$ & $\stackrel{l}{N o}$ & $(\%)$ & $\underset{N o}{2}$ & $(\%)$ & $\begin{array}{l}<2 c \\
\mathrm{No}\end{array}$ & $m_{(\%)}$ & $\begin{array}{c}\uparrow 32 \\
\text { No }\end{array}$ & $m_{(\%)}$ & $\begin{array}{l}\text { Sessile } \\
\text { No }\end{array}$ & $(\%)$ & $\begin{array}{l}\text { Pedu } \\
\text { No }\end{array}$ & $\begin{array}{c}\text { culated } \\
(\%)\end{array}$ \\
\hline $\begin{array}{l}\text { Polypectomy } \\
\text { Local surgical excision } \\
\text { Intestinal resection } \\
\text { Contact radiotherapy }\end{array}$ & $\begin{array}{l}40 \\
3^{\star} \\
39 \\
-\end{array}$ & $\begin{array}{l}48 \cdot 8 \\
36 \\
47 \cdot 6\end{array}$ & $\begin{array}{r}20 \\
21 \\
19 \\
4\end{array}$ & $\begin{array}{r}31 \cdot 3 \\
32 \cdot 8 \\
29 \cdot 7 \\
6 \cdot 2\end{array}$ & $\begin{array}{r}20 \\
4 \\
10 \\
-\end{array}$ & $\begin{array}{l}58 \cdot 8 \\
11 \cdot 8 \\
29 \cdot 4\end{array}$ & $\begin{array}{l}40 \\
17^{\star} \\
34 \\
4\end{array}$ & $\begin{array}{r}42 \cdot 1 \\
17 \cdot 9 \\
35 \cdot 8 \\
4 \cdot 2\end{array}$ & $\begin{array}{r}- \\
3 \\
14\end{array}$ & $\begin{array}{l}17 \cdot 6 \\
82 \cdot 4\end{array}$ & $\begin{array}{r}33 \\
4 \\
17 \\
1\end{array}$ & $\begin{array}{r}60 \cdot 0 \\
7 \cdot 3 \\
30 \cdot 9 \\
1 \cdot 8\end{array}$ & $\begin{array}{l}27 \\
20^{\star} \\
40 \\
3\end{array}$ & $\begin{array}{r}30 \cdot 0 \\
22 \cdot 2 \\
54 \cdot 4 \\
3 \cdot 3\end{array}$ & $\begin{array}{r}18 \\
15 \\
37 \\
4\end{array}$ & $\begin{array}{r}24 \cdot 3 \\
20 \cdot 3 \\
50 \cdot 0 \\
5 \cdot 4\end{array}$ & $\begin{array}{c}36 \\
8^{\star} \\
20 \\
0\end{array}$ & $\begin{array}{l}56 \cdot 3 \\
12 \cdot 5 \\
31 \cdot 2\end{array}$ \\
\hline
\end{tabular}

$1^{\star}$ Colotomy in three cases; $†$ unknown in one case; $\ddagger$ unknown in eight cases.

nant rectal polyps underwent local surgical excision (14.4\%): transanal resection in 20 (completed in one by contact radiotherapy) and Kraske resection in one case. Laparotomy was performed in 61 patients (41.8\%). Lymph node involvement was observed in three cases $(4 \cdot 9 \%)$. Of these, one was moderately differentiated, one was poorly differentiated and one was mucinous. The surgical treatment was right hemicolectomy in two cases, segmental resection in 34 , total colectomy in three, anterior resection of the rectum in 16, abdominoperineal resection in three, and colotomy in three. In 10 of the operated patients, resection was performed after an apparently incomplete endoscopic polypectomy. Evidence of residual tumour was found in two cases without lymph node metastasis. Four malignant sessile polyps were treated by contact radiotherapy alone $(2 \cdot 7 \%)$. The influence of localisation, size, macroscopic type of growth, and stage of diagnosis on treatment is given in Table $\mathrm{I}$.

\section{SURVIVAL}

The postoperative mortality was 5 of $61(8 \cdot 2 \%)$ after intra-abdominal surgery, 1 of $21(4 \cdot 8 \%)$ after surgical local excision, and 0/60 after polypectomy $(p<0.05)$. All deaths occurred in patients over 65 years. Thirty two patients died of other causes during the follow up period (Table II) $-8(25 \cdot 0 \%)$ from cancer recurrence, 2 $(6.2 \%)$ from metachronous colorectal cancer, and $21(65 \cdot 6 \%)$ from intercurrent medical illness. In this last group mortality was higher in patients treated by endoscopic polypectomy than in those treated by surgery $(p<0.01)$.

The overall five year crude survival rate was $71 \cdot 8 \%$, the corresponding net survival rate being $90 \cdot 1 \%$. Table III lists patients' characteristics in relation to the five year crude and net survival rates. Sex, histology of adenoma, degree of differentiation of the carcinoma, and macroscopic growth were not important prognostic

TABLE II Causes of death after treatment of malignant polyps

\begin{tabular}{|c|c|c|c|}
\hline & \multirow[b]{2}{*}{$\begin{array}{l}\text { Endoscopic } \\
\text { polypectomy } \\
(n=60) \\
N o(\%)\end{array}$} & \multicolumn{2}{|c|}{ Surgical treatment } \\
\hline & & $\begin{array}{l}\text { Local } \\
\text { excision } \\
(n=21) \\
\text { No }(\%)\end{array}$ & $\begin{array}{l}\text { Resection } \\
(n=61) \\
N o(\%)\end{array}$ \\
\hline \multirow{5}{*}{$\begin{array}{l}\text { Postoperative death } \\
\text { Cancer recurrence } \\
\text { Metachronous colorectal } \\
\text { cancer } \\
\text { Intercurrent medical } \\
\text { illness } \\
\text { Unknown }\end{array}$} & 0 & $1(4 \cdot 8)$ & $5(8 \cdot 2)$ \\
\hline & $3(5 \cdot 0)$ & $1(4 \cdot 8)$ & $4(6 \cdot 6)$ \\
\hline & $1(1 \cdot 7)$ & $1(4 \cdot 8)$ & 0 \\
\hline & $15(25 \cdot 0)$ & $2(9.5)$ & $4(6.6)$ \\
\hline & $1(1 \cdot 7)$ & $2(9 \cdot 3)$ & $\begin{array}{l}4(6 \cdot 6) \\
2(3 \cdot 3)\end{array}$ \\
\hline
\end{tabular}

factors. Age was a significant factor. Patients more than 70 years of age had a worse survival curve than younger patients $(\mathrm{p}<0 \cdot 05)$.

In eight cases local recurrence or distant metastasis, on both (mean follow up period $64 \cdot 3$ months) occurred 14 to 81 months after the initial treatment (mean 44.9 months). Cumulative recurrence curves according to the type of treatment are given in Figure 2. The five year cumulative recurrence rate was $8.9(3.9) \%$ after surgery (laparotomy and local excision) and $11 \cdot 3$ (6.9)\% after endoscopic polypectomy (NS). Three metachronous colorectal cancers were diagnosed two years after the initial cancer in two cases and six years later in one.

\section{Discussion}

These data describe for the first time the epidemiological characteristics of malignant polyps in a well defined population. The frequency of malignant polyps among other large bowel tumours was lower in the Côte d'Or than in hospital based studies. For instance, in the Erlangen registry of colorectal tumours, malignant polyps (defined as carcinoma with submucosal spread) represented $9 \cdot 3 \%$ of all colorectal cancers $^{6}$ and were present in $10.2 \%$ of patients with adenomas. ${ }^{7}$ Many of the discrepancies in the evaluation of the frequency of these lesions lie within the selection bias of hospital series. The results underline the fact that in a well defined population large bowel cancers diagnosed at the stage of malignant polyps remains relatively rare, although the incidence of diagnosed malignant polyps increased significantly over the 10 year period of the study.

The sex ratio for large bowel cancer in the Côte D'or was similar to the sex ratio for malignant polyps. Age specific incidence curves show the same trends until age 75 , with similar rates in men and women until 50 and then a male predominance. The apparent decline in the age specific incidence of malignant polyps after the age of 75, which is not observed for other large bowel cancers, ${ }^{8}$ may be because colonoscopy is less frequently undertaken for minor symptoms in older patients.

The segmental distribution of malignant polyps within the large bowel was not similar to the distribution site of cancers. In the Côte d'Or, $43.4 \%$ of invasive large bowel cancers were in the rectum, $28.2 \%$ in the sigmoid, and $15.6 \%$ in the caecoascending colon. ${ }^{8}$ Similar discrepancies in the location of early and advanced large bowel cancer have already been reported. ${ }^{9}$ These data suggest that the adenomacarcinoma sequence is less important in the pathogenesis of right colon 
TABLE III Five year survival rates (\%) after treatment of malignant colorectal polyps (values mean $(S E M))$

\begin{tabular}{|c|c|c|c|}
\hline & No of patients & $\begin{array}{l}\text { Crude } 5 \text { year } \\
\text { survival }\end{array}$ & $\begin{array}{l}\text { Net } 5 \text { year } \\
\text { survival }\end{array}$ \\
\hline Total & $144^{\star}$ & $71 \cdot 8(4 \cdot 0)$ & $90 \cdot 1(2 \cdot 6)$ \\
\hline \multicolumn{4}{|l|}{ Sex: } \\
\hline $\begin{array}{l}\text { Men } \\
\text { Women }\end{array}$ & 84 & $68 \cdot 8(5 \cdot 3)$ & $87 \cdot 4(3 \cdot 7)$ \\
\hline Women & 60 & $76 \cdot 1(5 \cdot 9)$ & $93 \cdot 7(3 \cdot 6)$ \\
\hline \multicolumn{4}{|l|}{ Age: } \\
\hline$<70$ Years & 68 & $79 \cdot 5(5 \cdot 2)$ & $94 \cdot 8(3 \cdot 0)$ \\
\hline$\geq 70$ Years & 76 & $65 \cdot 0(5 \cdot 8)$ & $86 \cdot 0(4 \cdot 1)$ \\
\hline \multicolumn{4}{|l|}{ Location: } \\
\hline Colon & 81 & $70 \cdot 6(5 \cdot 2)$ & $85 \cdot 6(4 \cdot 0)$ \\
\hline Rectum & 63 & $74.0(5.9)$ & $96 \cdot 0(2 \cdot 9)$ \\
\hline \multicolumn{4}{|l|}{ Histology of adenoma $†$ : } \\
\hline Tubulous & 60 & $67 \cdot 2(6 \cdot 1)$ & $87 \cdot 7(4 \cdot 4)$ \\
\hline Villous content & 78 & $75 \cdot 9(5 \cdot 2)$ & $91 \cdot 3(3.5)$ \\
\hline \multicolumn{4}{|l|}{ Histology of carcinomat: } \\
\hline Well differentiated & 64 & $71 \cdot 7(5 \cdot 9)$ & $88 \cdot 6(4 \cdot 0)$ \\
\hline Moderately differentiated & 75 & $71 \cdot 2(5 \cdot 6)$ & $92 \cdot 0(3 \cdot 5)$ \\
\hline \multicolumn{4}{|l|}{ Treatment : } \\
\hline Endoscopic polypectomy & 60 & $63 \cdot 6(6 \cdot 7)$ & $95 \cdot 9(2 \cdot 8)$ \\
\hline Surgical local & 19 & $72 \cdot 4(10 \cdot 6)$ & $86.8(8.9)$ \\
\hline $\begin{array}{l}\text { Excision } \\
\text { Surgical resection }\end{array}$ & 62 & $76.4(5.5)$ & $85.4(4.5)$ \\
\hline \multicolumn{4}{|l|}{ Stage of diagnosis: } \\
\hline Stage I & 34 & $68 \cdot 9(9 \cdot 5)$ & $93 \cdot 8(6 \cdot 1)$ \\
\hline Stage II & 110 & $71 \cdot 5(4 \cdot 5)$ & $88 \cdot 5(3 \cdot 1)$ \\
\hline \multicolumn{4}{|l|}{ Macroscopic growth“: } \\
\hline Pedunculated & 72 & $74 \cdot 5(5 \cdot 8)$ & $92.4(3.8)$ \\
\hline Sessile & 64 & $70 \cdot 9(5 \cdot 6)$ & $87 \cdot 3(3 \cdot 9)$ \\
\hline
\end{tabular}

^Two patients with incomplete follow up were not included. Survival not given for small groups. $\dagger$ carcinomatous polyps six cases; $\neq$ poorly differentiated adenocarcinoma one case, mucoid carcinoma
one case, histology of carcinoma unknown three cases; $§$ contact radiotherapy three cases; \# unknown eight cases.

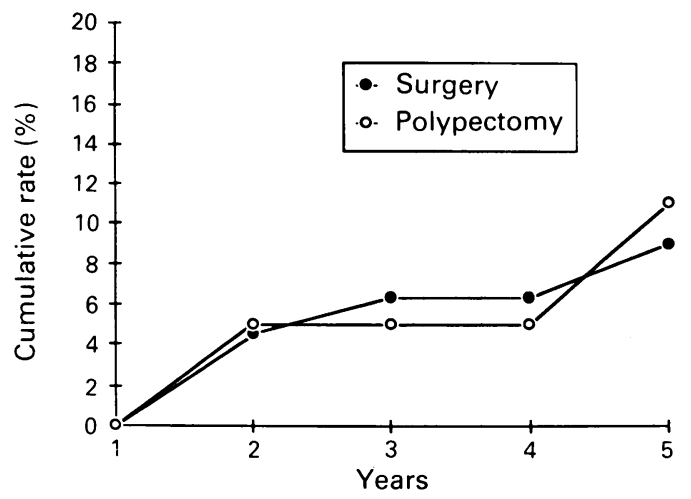

Figure 2: Cumulative recurrence rates of carcinoma according to the type of treatment of malignant large bowel polyps.

mortality is very low in patients under 65 years ( $0 \%$ in this series), but our results suggest that it can be relatively high in older patients. Many of the discrepancies in the operative mortality rates probably lie in patient selection. A relatively poor physical condition of the overall treated population is suggested by the high mortality from intercurrent medical disease. The proportion of patients in good physical condition seems to be higher among those seen in specialised endoscopy units. This may explain why the crude survival rates were lower in this series than in hospital based series. Five year survival rates taking account only of deaths from cancer were higher, between 85 and $95 \%$. The significant operative risk in patients who are in a poor physical condition, underlined by our population based data, must be taken into account in deciding on treatment.

A suspicion of incomplete resection of a malignant polyp represents the major indication for surgery after endoscopic polypectomy. ${ }^{231113}$ A positive polypectomy margin does not necessarily mean that residual carcinoma is present, because the electrocautery current causes a coagulative necrosis around the margin of excision. ${ }^{3}$ Only two of the 10 patients who underwent endoscopic resection of a carcinoma with a positive or close polypectomy margin and a subsequent colectomy had residual cancer in the bowel wall. In the near future, the echoendoscopic probe that can be inserted via the biopsy channel of the colonoscope may allow us to distinguish accurately between patients with or without residual cancer in the bowel wall. At present, if there is any doubt on the completeness of excision, surgery must be proposed.

The possibility of lymph node metastasis is another indication for complementary surgery. In three of 61 cases (4.9\%) treated by surgical resection in this series, metastatic lymph node involvement was found. In the published reports the frequency of lymph nodes metastasis has varied from 0 to $28 \cdot 6 \%$, the mean value being $9 \cdot 6 \% .^{+}$It must be emphasised that surgical resection does not reduce the risk of dying from cancer recurrence. In this study, the cumulative recurrence rates were similar for endoscopic polypectomy alone and surgical resection. These data suggest that the benefit of surgery is small, probably because the disease has often already spread with subclinical metastases in the case of positive nodes. Because of the operative risk, it is 
important to identify those patients who are at high risk of lymph node metastasis. It becomes increasingly obvious that adenocarcinoma in a pedunculated polyp that has been completely excised has a very low metastasing potential: $3 \%$ according to a review of the published reports. ${ }^{+}$As it is well established, that more than $50 \%$ of patients with resected colorectal cancer and positive lymph nodes will die from their cancer, only $1.5 \%$ will benefit from surgery, which is lower than the postoperative mortality rate. These patients must be treated conservatively. The risk of lymph node metastasis is higher in pedunculated polyps with invasion of the stalk or sessile polyps with invasive cancer. Recent reports suggest that in these cases venous or lymphatic invasion, or both, are good predictors of lymph node metastasis. ${ }^{1+15}$ If present further surgical treatment is indicated. No firm conclusion can be drawn from our data because this information was not always accurately recorded. An active search for these factors seems to be essential in the future. Surgery was also recommended by many authors for poorly differentiated adenocarcinoma, mucinous adenocarcinoma, and signet ring cell adenocarcinoma. ${ }^{1216}$ In patients with a high operative risk, the decision about segmental resection must be made on an individual basis taking account of the potential benefit of surgery and the operative risk.

The authors thank Professor Michiels and Justrabo and Doctors Bastien, Bordes, Dusserre, Dusserre-Guion, Michiels-Marzais, Morlevat, Mottot, Peny, Roignot and the gastroenterologists: Bataillon, Berthe, Bonniaud, Carli, Cemachovic, Courtois, Gambert, Garaudet, Jacquot, Joyeux, Kessler, Klepping, Maringe, Massart, Meny, Michalet, Munschi, Riot Roy, and Villand for their contributions.
1 Coutsofides T. Colonoscopy and the management of polyps containing invasive carcinoma. Ann Surg 1978; 188: 638-41.

2 Metayer P, Le Bihan M, Metayer J, Cailliez D, Collin R, Hemet J. L'exérèse endoscopique des polypes malins du colon est-elle une thérapeutique suffisante? Gastroenterol Clin Biol 1980; 4: 386-92.

3 Morson BC, Witeway JE, Dones GA, Macrae FA, Williams CB. Histology and prognosis of malignant colorectal polyps treated by endoscopic polypectomy. Gut $1984 ; 25: 437-44$.

4 Nivatvongs S. Management of polyps containing invasive carcinoma. In: Codner IJ, Frey RD, Roe JP, eds. Colon, carcinoma. In: Codner IJ, Frey RD, Roe JP, eds. Colon,
rectal and anal surgery. St. Louis: CV Mosby, 1985: 183-8.

5 Morson BC, Sobin LH. Histological typing of intestinal tumours. International classification of tumors, 15. Geneva: WHO, 1976 .

6 Hermanek P, Gall FP. Early (microinvasive) colorectal carcinoma. Pathology, diagnosis, surgical treatment. Colorectal Dis 1986; 1: 79-84.

7 Hermanek P, Fruhmorgen P, Guggenmoss-Holtzmann I Altendorf A, Matek W. The malignant potential of colorectal polyps. A new statistical approach. Endoscopy 1983; 15:1620.

8 Faivre J, Bedenne L, Boutron MC, Milan C, Collonges R, Arveux P. Epidemiological evidence for distinguishing subsites of colorectal cancer. $\mathcal{F}$ Epidemiol Community Health 1989; 43: 356-61.

9 Matek W, Hermanek P, Demling L. Is the adenoma-carcinoma sequence contradicted by different location of colorectal adenomas and carcinomas. Endoscopy 1986; 18: 17-8.

10 Faivre J, Boutron MC, Bataillon P. Epidemiology of adenoma clinical data. In: Faivre J, Hill MJ, eds. Causation and prevention of colorectal cancer. Amsterdam: Elsevier Science, 1977: 29-37.

11 Willcox GM, Beck JR. Early invasive cancer in adenomatous colonic polyps (malignant polyps). Evaluation of the therapeuctic options by decision analysis. Gastroenterology 1987 92; 1159-68.

12 Williams CB, Whiteway JE. Conservative management of malignant polyps: St Mark's results at 5 vears. In: Fenogliomreiser CM, Rossini FP, eds. Adenomas and adenomas containing carcinoma of the large bowel. New York: Raven containing carcinom

13 Haggitt RC, Glotzbach RE, Soffer EE, Wruble LD. Prognostic factors in colorectal carcinomas arising in adenomas: implications for lesions removed by endoscopic polypectomy. Gastroenterology i $985 ; 89$ : 328-36.

14 Cranley JP, Petras RE, Carey WD, Paradis K, Sivak MV When is endoscopic polypectomy adequate therapy for colonic polyps containing invasive carcinoma? Gastroenterology 1986; $91:$ 419-27.

15 Muller S, Chesner IM, Egan MJ, Rowlands DC, Collard MJ Swarbrick ET, et al. Significance of venous and lymphatic invasion in malignant polyps of the colon and rectum. Gut invasion in malignant

16 Sugihara K, Muto T, Morioka Y. Management of patients with invasive carcinoma removed by colonoscopic polypectomy. Dis Colon Rectum 1989; 10: 829-34. 